\title{
The Nutrition Label - Which Information is Important to The Consumer?
}

\author{
Mr. Gautam Donga, Dr. Naresh Patel
}

\begin{abstract}
Purpose - To study importance given by consumer to the various information on nutrition label, and to survey consumer of various cities of Gujarat, India, to determine the percentage of consumers who read nutrition label, how frequently they read nutrition label while purchasing different food products.
\end{abstract}

Methodology - Consumers from Ahmedabad, Surat, Vadodara and Rajkot were surveyed using a structured questionnaire. The survey has been conducted at outside the various retail stores in all the four cities. Questionnaire contain questions on various components of Nutrition label, frequency of reading nutrition label while purchasing specific categories of products and demographic information $(n=2192)$.

Findings - Of 2192 respondents, 95.8 percent were aware about nutrition label and 88 percent reported reading nutrition label. The most important information on nutrition label for respondents were 'Total fat', 'Calories from fat' and 'Cholesterol'. When ask about specific product categories, read nutrition label more frequently were snacks, soft drinks, and chocolates.

Index Terms - Nutrition labeling, Food labeling, Nutrition, India.

\section{INTRODUCTION}

The diet-related health issues have been increased intensely from last few years across the globe. Now, it's really important to take corrective steps in this field considering the fact that the people suffer a lot from the health risks like blood pressure, cardio disease, and high body mass index. In response to this serious issue of health risk, the governments of various countries has raise the concern about different issues like eating habit of people, physical activity, and attitude towards healthy living. In this situation, self-discipline on the consumption of food is really very important. The nutrition and calories requirement varies from person to person based on their physic. It became really important that the consumer must have knowledge of the product they consuming.

The best way to inform the consumer about the product and the nutrients it carries is to provide information about the product. Food label on the product plays the role of informing the consumer about the product, its ingredients and nutrients it contains. A label serves the following three primary

Mr. Gautam Donga, Department of Management Uka Tarsadia University, Bardoli, India

Dr. Naresh Patel, Centre for Management Studies, Dharmsinh Desai University, Nadiad, India functions: (i) it provides basic product information (including common name, list of ingredients, net quantity, shelf life, grade/quality, vegetarian society logo, country of origin, name and address of manufacturer, dealer or importer and food standards agency; (ii) it provides health, safety, nutrition information which includes instructions for safe storage, handling, nutrition information such as quantity of fats, protein, carbohydrate, vitamins \& minerals and preservatives, colors, if used any, quantity per serving of stated size of food (in the nutrition facts table) and specific information on products for special dietary use; (iii) it also acts as a vehicle for food marketing promotion and advertising promotional information and claims such as 'low fat', 'cholesterol free', 'high source of fiber', 'natural', 'organic', 'no preservatives added' and the like. Labels help people sometimes in some cases if they have the knowledge or motivation to use the information, which may or may not be in a format they can understand. Food labeling is found to be a very vital public health tool aimed at providing consumers with information which may influence their purchasing decisions.

According to the FDA in the USA, a label is the primary point of contact between the producer and the purchaser and should be thought of as an integral part of the producer's marketing plan. According to the FDA (1998), a label should clearly and minimally state the name of the product, the net weight, the nutrition facts panel (nutrition label), the name and address of the manufacturer, and the brand name. According to the Federal Food, Drug, and Cosmetic Act, the labeling is "a written, printed, or graphic matter (i) upon any article or any of its containers or wrappers or (ii) accompanying such article at any time while a device is held for sale after shipment or delivery for shipment in interstate commerce". The food labels act as a signaling mechanism by which food companies assure their potential consumers regarding their sound quality control practices.

One of the most important components of a food label is nutrition label which is available on the packed food product. Nutrition label alone is likely to offer limited success to public health communication method but it can make a small but important contribution towards making informed food choices. Consumers can use health claims, which appear on the food packages to identify foods with certain nutrition qualities related to risk factors and wellness. Consumers' ability to choose their diets somewhat depends on the quantity and quality of information available through a variety of sources, including nutrition panel food labels (Caswell and Padberg 1992). The following are Components of Nutrition Label; 


\section{A. Serving Size}

At the top of the food label there is serving size. It shows the quantity of one portion consumer by a person from package. Mostly the total weight of the pack does not consider as the normal serving size. This shows how big the serving is and how many servings the package contains. A package of food mostly contains multiple serving. Serving sizes are mention in familiar terms like, "cups" or "pieces." The nutrition information like calories, sodium, and fiber given on the label is based upon one serving of the food. In short, it's the key to the information on the Nutrition label.

\section{B. Amount of Calories:}

The calories given are for one serving of the food. It is the energy provided by food. The product which is fat-free is not necessarily a calorie free.

\section{Calories from Fat:}

It shows the calories from the product intake come from the fat. These calories shown on the label are as per serving. As a general rule, this type of calories below 40 is considered as "low", 100 or below that is "moderated, and 400 or more than that is "high".

\section{Total fat:}

Fat is a major source of energy for the body. It also helps to absorb certain important vitamins. There are different types of dietary fat. Some have health benefits when eaten in small quantities, but others do not.

\section{E. Saturated Fat:}

It is a type of fat that is solid at room temperature. It is usually animal-based. This type of fat can raise cholesterol levels in the blood, which leads to heart disease.

\section{F. Trans Fat:}

It is a type of fat that is created when liquid fat is turned into solid fat during manufacturing. The trans-fat has no daily value, and should be replaced with unsaturated fat in your diet whenever possible.

\section{G. Unsaturated Fat:}

It is a type of fat that is liquid at room temperature. The unsaturated fat is healthful if eaten in moderation. Its consumption in small amounts can even help lower cholesterol levels!

\section{H. Cholesterol}

Cholesterol is the transporters of fat. Cholesterol is helpful in certain important body functions, like making hormones, digesting dietary fats, and building cell walls.

There are two types of cholesterol found in the bloodstream. The High-density lipoprotein (HDL) is good and the Low-density lipoprotein (LDL) is bad for body. Saturated fat is the main source of LDL than anything else in the diet.

\section{Salt/Sodium}

The words "salt" and "sodium" is often used interchangeably. Salt/Sodium is important in the diet, but too much sodium might lead to high blood pressure and risk of heart disease.

\section{J. Total Carbohydrate}

It is the part of diet which affects blood glucose levels. Carbohydrate is primarily found in plant foods; the exception is dairy products, which contain milk sugar. The total carbohydrate indicates how many grams of carbohydrate are in 1 serving. There are several types of carbohydrate;

\section{K. Sugar:}

The grams of sugar listed include both natural sugars, from fruit or milk, and added sugars.

\section{Fiber:}

It is the part of food that can't be broken down during digestion. It plays an important role in keeping digestive system moving and in working order. The label doesn't indicate whether the fiber is "soluble" or "insoluble," but both are good for the health.

The grams of fiber are included in the total carbohydrate, so one can subtract it from the total carbohydrate. For example: if a product has the Total Carbohydrate Total $(12 \mathrm{~g})$ and Fibber is $4 \mathrm{~g}$, the NET Carbohydrate is $8 \mathrm{~g}$.

M. Proteins:

Proteins are large compounds made by combining smaller amino acids. Consuming too much protein may be harmful to the body. Protein should account for $10-35 \%$ of your daily caloric intake.

\section{Literature Review}

Bandara at el. (2016) has conducted research titled among faculty of Agricultural Sciences. The study resulted that the most important components of nutrition label for consumer were fiber, fat, and calories related information. One of the major factors for consumer in their purchasing decision is Monosodium Glutamate. Yong Kang et al. (2015) have conducted research among group of smokers were less likely to read fat and sugar content than non-smokers. Jasmina Ranilovic et al. (2011) have found that the most commonly referred items were fat and energy information. Information related to energy mostly referred by young respondents $15-24$ year than the older one. Mannell at el. (2006) have found that the consumer consulted nutrition labels mostly for fat content, and energy. The nutrition information related to energy, fat, protein, carbohydrate, fiber and vitamin played an important role in decision making process of buying certain food products. Sandria L. Godwin et al. (2006) have found that the most frequent readers of nutrition label mostly search for fat, sugar, and calories per serving. Patricia E. McLean-Meyinsse (2001) has found that the older consumers mostly search for the sodium content of food product. The study identified that consumers read the information more frequently on fat content than any other attribute. Angela Shine et al. (1997) have found that the respondents use nutrition label to evaluate cholesterol levels, distinguish between "good" and "bad" food products by checking amounts of fat. There was one research having contradiction with other research, conducted by Gupta and Dharni (2016). The researchers found that less noticed components by consumer in their purchase decision were fat, proteins and preservatives. This prompts research into the importance of nutrition components to determine (I) which components of nutrition labels are most important to consumers and; (II) how important nutrition label is relative to other labels on packed food products.

III. Methodology

This study aimed to identify the importance of various components of nutrition label in consumer decision making process. The food products considered in this study were 
chocolates, pasts and noodles, bread and ordinary bakery products, complementary foods for infants, soft drinks and snacks. The target populations surveyed was non-random sample of consumers. Respondents were surveyed at organized and unorganized retail store within the four cities of Gujarat, India. The questionnaire was pilot-tested on 40 respondents for clarity and accuracy. It consists of questions related to usage of labels in purchase decision making process, various components of nutrition label as well as food label they use most frequently in decision making. other than this data have also been collected on respondents" demographic characteristic (gender, age, income, education, marital status, household size, number of children below 18 in family, and any disease they have.) Total 2192 completed and acceptable questionnaire were collected.

IV. Results

Table 1. Demographic Profile of the Respondents

\begin{tabular}{|c|c|c|c|}
\hline & & $\begin{array}{l}\text { Freque } \\
\text { ncy }\end{array}$ & $\begin{array}{l}\text { Perce } \\
\text { nt }\end{array}$ \\
\hline \multirow{2}{*}{ Gender } & Male & 974 & 44.41 \\
\hline & Female & 1218 & 55.54 \\
\hline \multirow{4}{*}{ Age } & $18-29$ & 323 & 14.73 \\
\hline & $30-49$ & 641 & 29.23 \\
\hline & $50-64$ & 664 & 30.28 \\
\hline & 65 or more & 564 & 25.72 \\
\hline \multirow{4}{*}{$\begin{array}{l}\text { Monthly } \\
\text { Income }\end{array}$} & Below 10,000 & 82 & 3.74 \\
\hline & 10,000 to 25,000 & 586 & 26.72 \\
\hline & 25,001 to 40,000 & 835 & 38.08 \\
\hline & $\begin{array}{l}\text { More than } \\
40,000\end{array}$ & 689 & 31.42 \\
\hline \multirow{2}{*}{$\begin{array}{l}\text { Marital } \\
\text { Status }\end{array}$} & Single & 680 & 31.01 \\
\hline & Married & 1512 & 68.95 \\
\hline \multirow{6}{*}{ Education } & Below School & 236 & 10.76 \\
\hline & $\begin{array}{cc}\text { High } & \text { School } \\
\text { Completed } & \\
\end{array}$ & 509 & 23.21 \\
\hline & $\begin{array}{l}\text { University } \\
\text { Students }\end{array}$ & 325 & 14.82 \\
\hline & Graduation & 403 & 18.38 \\
\hline & Post Graduate & 710 & 32.38 \\
\hline & $\begin{array}{c}\text { Beyond } \\
\text { Post-Graduation }\end{array}$ & 9 & 0.41 \\
\hline \multirow{2}{*}{\begin{tabular}{ll}
\multicolumn{2}{c}{ Children } \\
below 18 \\
years \\
family
\end{tabular}} & Yes & 929 & 42.36 \\
\hline & No & 1263 & 57.59 \\
\hline \multirow{4}{*}{$\begin{array}{l}\text { BMI } \\
\text { Level }\end{array}$} & Underweight & 76 & 3.47 \\
\hline & Healthy & 1473 & 67.20 \\
\hline & Overweight & 560 & 25.55 \\
\hline & Obese & 83 & 3.79 \\
\hline
\end{tabular}

Of the 2192 respondents included in the sample, 55.54 percent were female and almost half of the consumers aged above 50 years. A majority of respondents (69.5 percent) were having monthly income more than Rs. 25,000. Majority of respondents ( 68.95 percent) were married and had at least above school education ( 89.2 percent). There were 57.59 per cent respondents had children aged below 18 and 76.2 percent respondents had healthy BMI.

Of the 2192 respondents 95.8 percent respondents were aware about nutrition label and almost 88 percent respondents reported using nutrition labels. There were 64.91 percent respondents claimed that they use nutrition label to avoid harmful nutrients and 62.31 percent married respondents agree with the statement that they use nutrition label just to have time pass.

Figure - 1 Respondents read nutrition label while purchasing different products

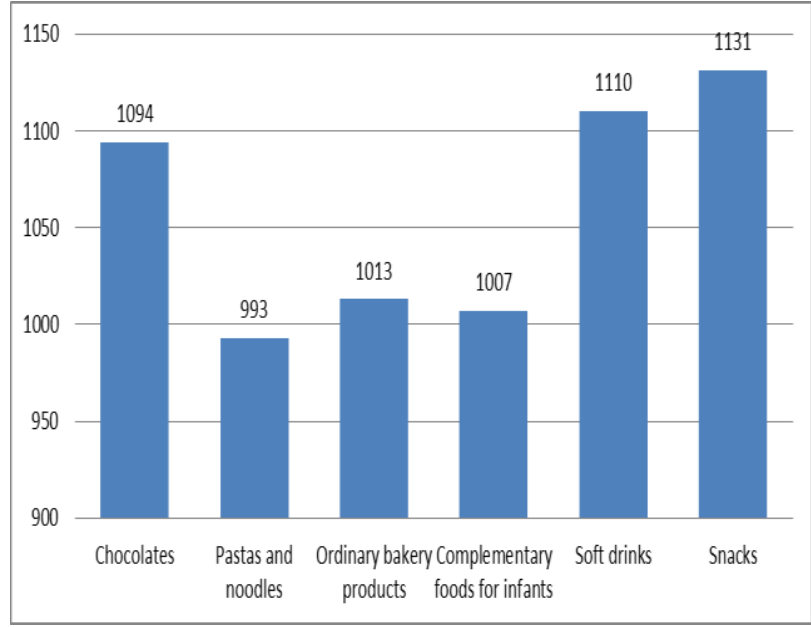

Most often respondents tends to read nutrition label on snacks (61.4 percent), which is followed by soft drinks (60.3 percent), chocolates (59 percent), ordinary bakery products (55 percent) and then complementary foods for infants (Figure - 1).

Figure - 2 Importance of nutrition information in purchasing decision

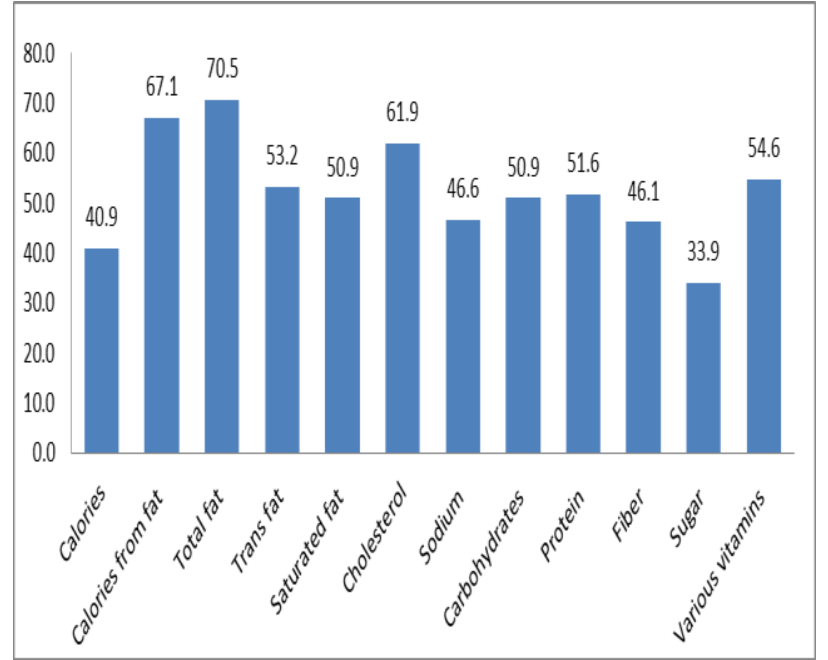

The most important nutrition information on nutrition label to respondents was Total Fat (70.54 percent), which is followed by Calories from fat (67.10 percent) and cholesterol on food labels (61.91 percent). While the least important information on nutrition labels were sugar (33.9 percent) and calories (40.9 percent) (Figure 2).

Kendall's tau-b has been applied to understand whether there is an association between various demographic factors and three most important nutrition information i.e. Total fats, Calories from fat, and cholesterol.

There were strong negative association between gender and 
importance given to total fat content which was statistically significant, $\tau \mathrm{b}=0.631, p=0.032$. It means that men give more importance total fat content compare to female. There were poor negative association found between demographic factors like age, marital status, child below 18 years in family and number of family members and importance given to total fat. BMI level and Monthly income are strongly positively associated with the importance given to total fat content which was statistically significant, $\tau \mathrm{b}=0.581, p=0.021$ and $\tau \mathrm{b}=0.712, p=0.025$ respectively. Monthly income was poorly positively related with importance given to total fat. Age, number of family members and BMI level were negatively related with the importance given to 'Calories from fat' and 'Cholesterol' information available on food label. Married respondents and having child below 18 in the family were giving less importance to the 'Calories from fat' and 'Cholesterol' information available on food label. Monthly income and education of respondents' positively related with the importance given to 'Calories from fat' and 'Cholesterol' information on food label. Female give more importance to 'Calories from fat' and 'Cholesterol' information compare to male. This information might be useful to the food manufacturers to provide more accurate information to target market segment. As there were variation in nutrition information consulted varies with variation in demographic factors, it's important for manufacturers to vary their product communication strategy.

Limitations of this study include only nutrition information from various food labels. The study didn't consider various reasons for not reading nutrition label or issues they are facing while reading nutrition label.

The majority of the consumer reported that they were aware about nutrition label and also read it frequently. Majority of nutrition label user, read nutrition label while purchasing snacks, soft drink and chocolates. The majority of consumer in this study reported that mostly they looking for information related to 'Total fat', 'Calories from fat' and 'Cholesterol' on nutrition label. Repondents with different demographic profile, have diffirent opinion towards various components of nutrition label. Food manufacturers can utilize this information to make changes in their food as well as to target the market segment.

\section{REFERENCES}

[1] B.E.S. Bandara, Maduwanthi, De Silva, and Warunasinghe. "Impact of food labeling information on consumer purchasing decision: with special reference to faculty of Agricultural Sciences." Procedia Food Science. Belihuloya: Elsevier Ltd., 2016. 309-313.

[2] Bandara, B.E.S., D.A.M. De Silva, B.C.H. Maduwanthi, and W.A.A.I. Warunasinghe. "Impact of food labeling information on consumer purchasing decision: with special reference to faculty of Agricultural Sciences." Procedia Food Science 6 (2016): 309-313.

[3] Caswell, Julie A., and Daniel I. Padberg. "Toward a More Comprehensive Theory of Food Labels." American Journal of Agricultural Economics 72, no. 2 (1992): 460-468.

[4] Cheah, Yong Kang , Foong Ming Moy, and Debbie Ann Loh. "Socio-demographic and lifestyle factors associated with nutrition label use among Malaysian adult." British Food Journal 117, no. 11 (2015): 2777-2787.

[5] Godwin, Sandria L., Leslie Speller-Henderson, and Cindy Thompson. "Evaluating the nutrition label: Its use in and impact on purchasing decisions by consumers." Journal of food Distribution Research 37, no. 1 (2006): 82-86.
[6] Gupta, Ketki, and Khushdeep Dharni. "Use and influence of nutrition labeling: an emerging market experience." Nutrition and Food Science 46, no. 3 (2016)

[7] Mannell, Ashley, Patricia Brevard, Rodolfo Nayga, Pierre Combris, Robert Lee, and Janet Gloeckner. "French consumers' use of nutrition labels." Nutrition \& Food Science (36) 3 (2006): 159-168.

[8] Nayga. "Determinants of consumers' use of nutritional information on food packages." Journal of Agricultural and Applied Economics 28, no. 2 (1996): 303-312.

[9] Patricia, E., and McLean Meyinsse. "An Analysis of Nutritional Label Use in the Southern UNited States." Journal of Food Distribution Research, 2001: 111-115.

[10] Petrovici, Dan, Andrew Fearne, Rodolfo Nayga, and Dimitris Drolias. "Nutritional knowledge, nutritional labels, and health claims on foods." British Food Journal 114, no. 6 (2012): 768-783.

[11] Priyadarshini, Vijayeta. "Awareness and use of food labelling informations among consumers in Bhubaneswar city." Food Science Research 5, no. 2 (2014): 114-119.

[12] Ranilović , Jasmina, and Irena Colić Barić. "Perceived barriers and motives to reading nutrition label among label 'non-users' in Croatia." Croatian Journal of Food Technology, Biotechnology and Nutrition 8 , no. 2 (2013): 52-57.

[13] Shine, Angela, Seamus O'Reilly, and Kathleen O'Sullivan. "Consumer use of nutrition labels." British Food Journal 99, no. 8 (1997): 290-296.

[14] Stuart, Stephen A. "The relationship between mandatory and other food label information." British Food Journal 112, no. 1 (2010): 21-31.

[15] Sun, Pi-Chuan, Hsien-Long Huang, and Fang_Yi Chu. "Factors instead of demographic characteristics related to nutrition label use." British Food Journal 117, no. 12 (2015): 1-18.

[16] Vemula, Sudershan, Subbarao Gavaravarapu, Vishnu Vardhana, Rao Mendu, Pulkit Mathur, and Laxmaiah Avula. "Use of food label information by urban consumers in India - a study among supermarket shoppers." Public Health Nutrition: 17, no. 9 (2013): 2106-2114.

[17] Zarkin, and Anderson. "Consumer and Producer Responses to Nutrition Label Changes." American Journal of Agricultural Economics 75, no. 5 (1992): 1202-1207.

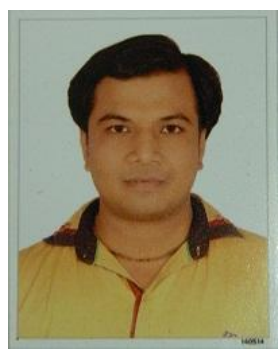

Mr. Gautam Donga, have completed his MBA from, Dharmsinh Desai University, Nadiad, India. $\mathrm{He}$ is pursing $\mathrm{PhD}$ from the same university. He has published research articles in the field of Nutrition labeling and digital marketing.

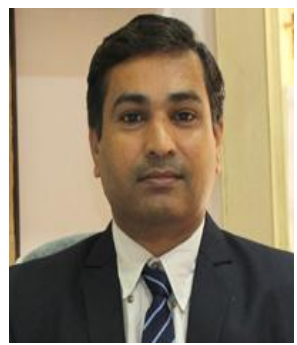

Dr. Naresh Patel has completed his PhD. in the field of Management (Marketing). He is Dean of faculty of Management and Information Sciences at Dharmsinh Desai University. He has published many research articles and also works on various Government projects. 